\title{
Development of a Health Education Application Smartphone-based "FoCED" to Increase Knowledge About Foot Care In Patients With Diabetes Mellitus
}

\author{
Djoko Priyono ${ }^{a) 1}$, Suriadi'1), Yoga Pramana ${ }^{11}$, and Junaidi2) \\ ${ }^{1}$ Jurusan Keperawatan, Fakultas Kedokteran, Univeritas Tanjungpura, Pontianak, Indonesia \\ ${ }^{2}$ Klinik PKU Muhammadiyah Kitamura Pontianak, Pontianak, Indonesia \\ a)Corresponding Author: djoko.priyono@ners.untan.ac.id
}

\begin{abstract}
One such complication is a diabetic foot ulcer that can lead to amputation. Various strategies are taken to reduce the occurrence of injuries in diabetic mellitus patients. One of them is through foot care education packaged by using interesting media. Through the development of smartphone-based applications, it aims to help patients and families perform the right foot care anytime and anywhere. The purpose of this activity is to develop educational media while increasing the knowledge of patients and families about performing foot care. The method used is to develop educational media in the form of applications on smartphones and measure knowledge score before and after education. In addition, during the education of patients and families, they will be followed up 3 times in 1 week. The targets of this program are diabetic patients and families at PKU Muhammadiyah Pontianak Clinic. The results of this activity show that smartphone-based "FoCED" foot care education applications can increase patient and family knowledge.
\end{abstract}

Key words: Foot Care, Education, Smartphone

\section{INTRODUCTION}

Every year, the number of people diagnosed with diabetes rises. Diabetes mellitus (DM) impacts around one in every eleven adults worldwide (Whiting et al., 2011). The number of persons with diabetes is expected to rise, as will the economic burden. With the rising prevalence of diabetes mellitus, health professionals must be able to recognize risk factors that can contribute to the disease's onset. Several studies show like obesity, lack of physical activity, hypertension, smoking, family history, and abnormal lipid metabolism were all identified as risk factors for diabetes mellitus. The more risk factors a person has, the greater a person's risk of developing diabetes mellitus (Apelqvist et al., 2008; Biswas et al., 2015).

Diabetes will also cause several other medical problems such as cardiovascular disease, peripheral neuropathy, retinopathy, kidney failure, dysfunction erection, ketoacidosis, hyperlipidemia, cognitive impairment and patients will be susceptible to other diseases such as pneumonia, decreased range of motion in lower extremity and occur diabetic foot ulcer which leads to amputation (Beckman et al., 2002; Kolluru et al., 2012; Whiting et al., 2011). According to other sources, about $50 \%$ of people who have diabetes get Diabetic Peripheral Neuropathy (DPN), which causes a loss of sensitivity in the lower extremities and also has a negative impact on the patient's quality of life (L Vileikyte et al., 2005; Loretta Vileikyte et al., 2005). One of the most common complications of diabetes is diabetic foot ulcers. About $15 \%$ of all patients with diabetes mellitus develop this complication, while $75-85 \%$ people who are getting it require amputation. (Chadwick et al., 2013)

A preliminary study conducted by a team at the "PKU Muhammadiyah Kitamura Clinic," one of Pontianak's wound care centers, collected data on 76 patients with diabetes ulcers who visited in one month. The high incidence of diabetic ulcer required preventive measures so that the quality of life of patients with diabetes mellitus can be improved. In addition to interventions in the form of education for patients, families also play an important role in supporting sustainable care. 
Several references suggest that patients with diabetes mellitus need to do foot care. Foot care is done to prevent the development of several factors that can cause injuries. (Michael E. Edmonds, Alethea V. M. Foster, 2004). This activity requires cooperation between patients and families in the long term. Home-based exercise/rehabilitation approach is quite an effective approach for conducting self-management for patients with diabetes mellitus. Studies show health education empowered by patients and families shows good adherence to chronic disease. (Demidowich et al., 2012; li et al., 2021).

One of the interventions that can be made to increase the understanding of patients and families about health education is interesting learning media. Based on the above background, the team felt the need to apply science and technology to providing education as an effort to maximize the provision of materials. In addition, based on the observations of the Community Service team, families accompanying diabetes melitus patients have a smartphone. For this reason, through this community service activity, the team will develop an Android-based application to provide foot care education for diabetes mellitus patients.

\section{METHOD}

This community service activity is carried out offline. The targets chosen in this activity are patients and families who are visiting the PKU Muhammadiyah Clinic. A total of 25 people were involved in this activity. Foot health education is carried out for 1 month from the date. After installing the application on the mobile phones of the patient, the patient will be reminded via telephone as many as three times a week to learn how to do foot care on their smartphones.

Prior to the implementation of health education, participants were asked to fill out a questionnaire to measure the level of knowledge about foot care steps. Then at the end of the meeting, participants filled out the questionnaire again. The pretest and posttest were carried out using an online form. The knowledge instrument used in this activity to assess knowledge is a questionnaire developed by the team based on sources accessed from https://www.diabetes.co.uk/diabetes-footcare.html (diabetes.co.uk, 2019)

\section{RESULTS}

The results obtained from this activity were only 25 clients followed to completion. Based on the level of knowledge of foot care steps, there was an increase after being given education from an average knowledge score of 46.25 to 76.83 with a $p$ value of $<0.05$. This means that the client knows and understands the material presented by the application that has been developed by the team.

\section{DISCUSSION}

The results of this activity indicate that an Android-based foot care application is one of the media that can increase client understanding of diabetes mellitus foot care. Among the provided self-care practice instructions, we provide step-by-step videos of foot care that are easy to follow and use easily available materials. We observed that compliance with the implementation of foot care at home requires follow-up from health workers which can be done through home visits or via phone. We emphasize that the role of the family is also very important in assisting patients in performing foot care so that they can improve the quality of life.

Based Blondon et al., (2014) Android-based smartphone applications can be an option as an educational media. These results are also consistent with Demidowich et al., (2012) stated that the interest of patients in the study using smartphones will increase and the patient gets a chance to open the material whenever and wherever. Foot care education is the first step in preventing injuries and the incidence of recurrent injuries in patients with diebetes mellitus. The advantage of health education through the "FoCED" application is that it is easy to use, attractive and simple. Users can access it anywhere, even if they are offline or not connected to the internet. However, the weakness of a product like this is that the user must have an Androidbased smartphone with a minimum operating system of Android 2.2. 


\section{CONCLUSIONS AND RECOMMENDATIONS}

Utilization of android-based smartphone applications in providing foot care education "FoCED" can be a means of health education in diabetes mellitus patients. The material in the form of videos contained in this application can provide efficiency and effectiveness to its users and help take action in performing foot care in patients with diabetes mellitus.

\section{ACKNOWLEDGMENTS}

This community service can be carried out well with the support of DIPA 2020 Universitas Tanjungpura

\section{REFERENCES}

Apelqvist, J., Bakker, K., Houtum, W. H. van, \& Schaper, N. C. (2008). Practical guidelines on the management and prevention of the diabetic foot Based upon the International Consensus on the Diabetic Foot ( 2007 ) Prepared by the International Working Group on the Diabetic Foot. Diabetes Metabolisme Research and Reviews, 24(October 2007). https://doi.org/10.1002/dmrr

Beckman, J. A., Creager, M. A., \& Libby, P. (2002). Diabetes and atherosclerosis; Epidemiology, pathophysiology, and management. American Medical Association, 287(19).

Biswas, A., Oh, P. I., Faulkner, G. E., Bajaj, R. R., Silver, M. A., Mitchell, M. S., \& Alter, D. A. (2015). Sedentary time and its association with risk for disease incidence, mortality, and hospitalization in adults a systematic review and meta-analysis. Annals of Internal Medicine, 162(2), 123-132. https://doi.org/10.7326/M14-1651

Blondon, K. S., Hebert, P. L., \& Ralston, J. D. (2014). An exploration of the potential reach of smartphones in diabetes. AMIA ... Annual Symposium Proceedings. AMIA Symposium, 2014, 289-296.

Chadwick, P., Edmonds, M., McCardle, J., \& Armstrong, D. (2013). Best Practice Guidelines: Wound Management in Diabetic Foot Ulcers. Wounds International.

Demidowich, A. P., Lu, K., Tamler, R., \& Bloomgarden, Z. (2012). Journal of Telemedicine and Telecare An evaluation of diabetes self-management applications for Android smartphones. Journal of Telemedicine and Telecare, 18(4), 235-238. https://doi.org/10.1258/jtt.2012.111002

diabetes.co.uk. (2019). Diabetes and Foot Care - Footcare for Diabetics 2019.

li, F. T., Ferreira, J. S. S. P., Junior, R. H. C., Donini, A., \& Verissímo, J. L. (2021). Feasibility of a home - based foot - ankle exercise programme for musculoskeletal dysfunctions in people with diabetes: randomised controlled FOotCAre. Scientific Reports, 11. https://doi.org/10.1038/s41598-021-91901-0

Kolluru, G. K., Bir, S. C., \& Kevil, C. G. (2012). Endothelial dysfunction and diabetes: effects on angiogenesis, vascular remodeling, and wound healing. International Journal of Vascular Medicine, 2012(Figure 1), 918267. https://doi.org/10.1155/2012/918267

Michael E. Edmonds, Alethea V. M. Foster, L. J. S. (2004). A PRACTICAL MANUAL OF; Diabetic Foot Care. Blackwell Publishing Ltd.

Vileikyte, L, Leventhal, H., Gonzalez, J., Peyrot, M., Rubin, R., Ulbrecht, J., Garrow, A., Waterman, C., Cavanagh, P., \& Boulton, A. (2005). Diabetic Peripheral Neuropathy and Depressive Symptoms. Diabetes Care, 28(10), 2378-2383. http://search.ebscohost.com/login.aspx?direct=true\&db=a9h\&AN=18549083\&site=ehostlive

Vileikyte, Loretta, Leventhal, H., Gonzalez, J. S., Peyrot, M., Rubin, R. R., Ulbrecht, J. S., Garrow, A., Waterman, C., Cavanagh, P. R., \& Boulton, A. J. M. (2005). Diabetic Peripheral Neuropathy and Depressive Symptoms. Diabetes Care, 28(10), 2378-2383. https://doi.org/10.2337/diacare.28.10.2378

Whiting, D. R., Guariguata, L., Weil, C., \& Shaw, J. (2011). IDF diabetes atlas: global estimates of the prevalence of diabetes for 2011 and 2030. Diabetes Research and Clinical Practice, 94(3), 311-321. https://doi.org/10.1016/j.diabres.2011.10.029 


\section{APPENDIX}

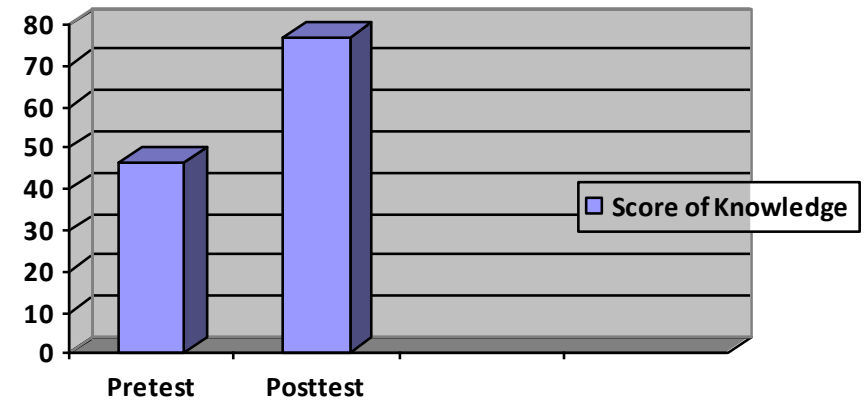

Figure 1. Pre-test and post-test

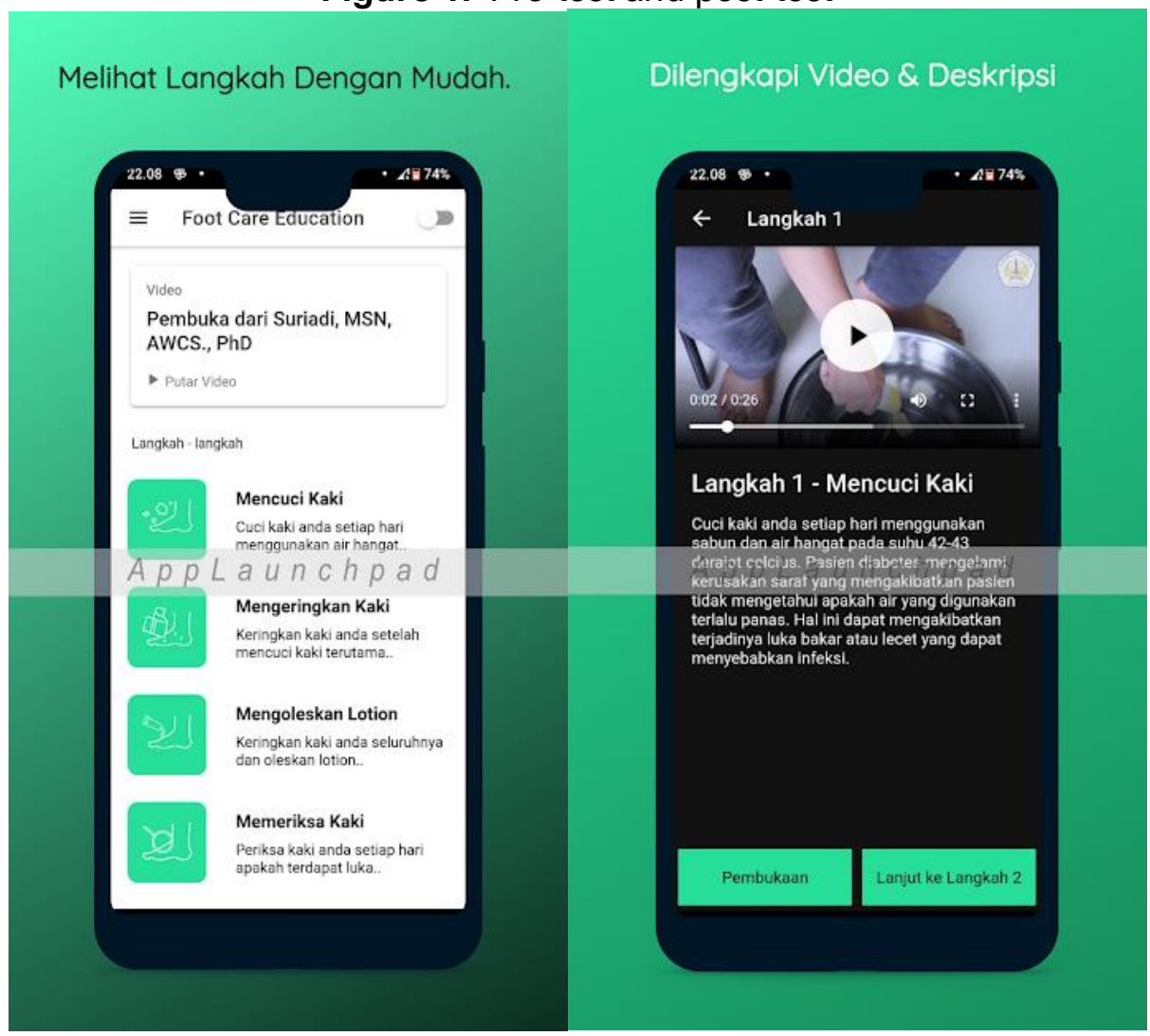

Figure 2. Application https://play.google.com/store/apps/details?id=com.test.foced 